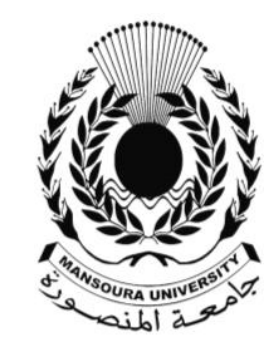

جامعة المنصـورة الماني

$$
\text { كليـة الآداب }
$$

\title{
الشكلات الناجمة عن الصراع بين أم الزوج والزوجة : دراسة حالة بإحدى قري محافظة الدقهلية.
}

\author{
إعـــ/د \\ د/ رقية محمد أحمد هلال زهري \\ دكتوراه في علم الاجتماع
}

مجـلة كلــية الآداب - جـامعـة المنصــورة

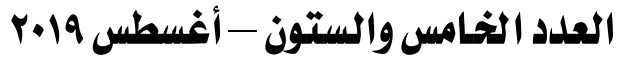




\section{المشكلات الناجمة عز الصراع بيز أم الزوج والزوجة : دراسة حالة بإِدهى قريى محافظة الدقهلية.}

\section{د/ رقية محمد أحمد هلال زهري}

\section{ملغص البعث:}

هدفت الدراسة إلى تحديد طبيعة الصراع بين أم الزوج والزووجة، وتحديد العوامل الدسبية له، والكثف عن الدشكلات الناجمة عنه.

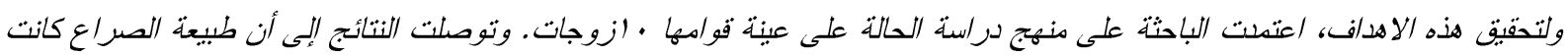

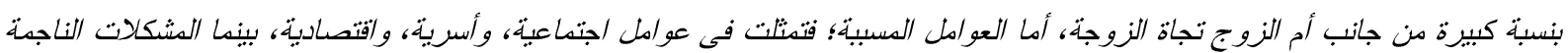
فكانت /جتماعية، ونفسية وجسية والبة وعصبية، واقتتصادية.

Abstract

The study aimed to determine the nature of the conflict between the husband and wife, and identify the factors causing it, and detect the problems caused by it . To achieve these goals, the researcher relied on a case study on a sample of 10 wives. The results found that the nature of the conflict was largely by the mother of the husband towards the wife, while the causative factors were social, family, and economic factors, while the resulting problems were social, psychological, physical, nervous and economic.

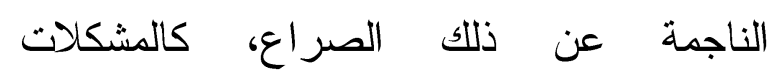

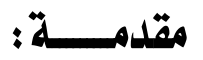
الاجنماعية مثل التفكك الأسري، و التتمر العائلي ضد الزوجة، وضعف الروابط العائلية بين

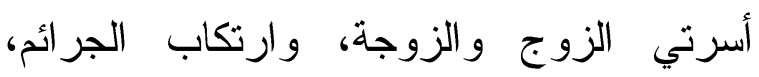
و التهديد بالزواج من أخرى، والخيانة الزوجية، وانية و المشكلات النفسية كالاكتئاب و الاحباط و القلق ونق

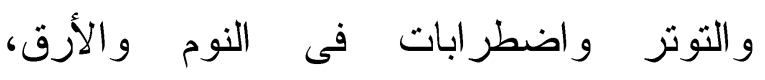
والجسدية كالاضطرابات فى الجهاز الهضيمي والاتئي

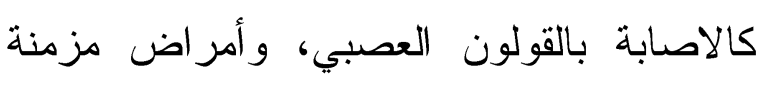
كالاصابة بالسكر، ومشاكل فى الجهاز التتفسي كالاصابة بحساسية الصدر، ومشاكل فى الجهاز العصبي كالصرع، ومشكلات اقتصادية؛ كعدم تحمل مصاريف الزوجه، و البخل. أولاً : مشكلة الدراسة :

تمر العديد من الأسر فى المجتمعات

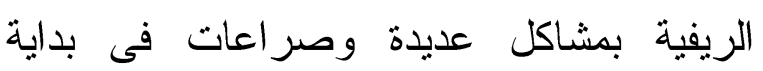
تكوينها خاصة الصراع بين أم الزوج و الزوجة بسبب النقافة السائدة و العادات و التقاليد الخاطئة

ان استقرار المجتمعات ورفاهيتها نرتبط

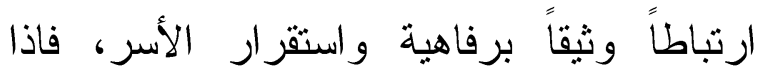

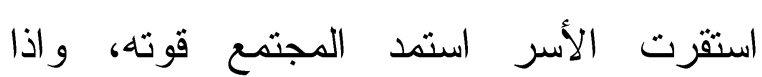
تخلخلت الأسر ساد الاضطر اب وعدم الاستقر ار و انعكس على المجتمع. من الطبيعي أن تمر الأسر المصرية

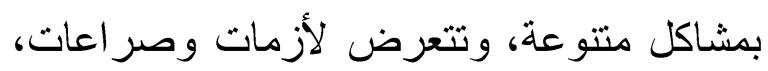

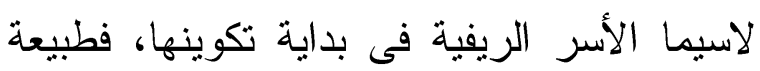
الحياة الريفية تكون فيها صرعات كثيرة بين الزوجة الجديدة وأم الزوج نظراً لثقافة النظرة السائدة للزوجة، والتتشئة الاجتماعية، ووسائل

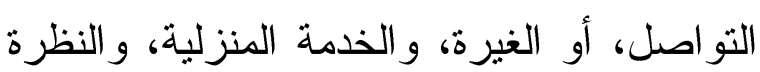
لمال الزوج المسافر. و هذه الصراعات تجعل ولئل

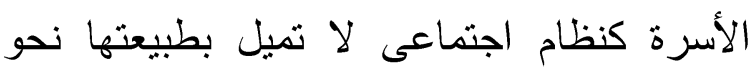

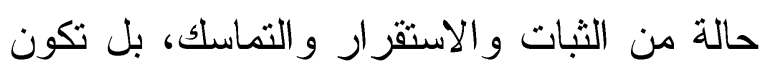
مصدر لاحداث تغييرات اجتماعية وتتفاوت الصراعات فى حدتها بسبب كثرة المشكلات 


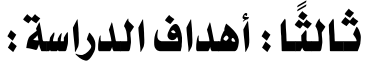

1-تحديد طبيعة الصراع بين أم الزوج والزوجة، من وجهة نظر علم الاجتماع بوصفه علم يهتم بتتاول الظاهرة من جميع جو انبها، وهذا ما يعطي لنا صورة شاملة إلى حد كبير لطبيعة الظاهرة

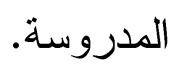

ץ- تحديد العوامل المسببة للصر اع بين أم

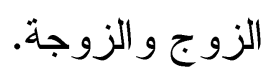

ب- الكثف عن المشكلات الناجمة عن

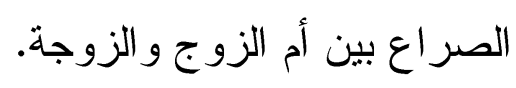

رابعًا : تساؤلات اللدراسة :

ا. ما طبيعة الصراع بين أم الزوج

$$
\text { و الزوجة؟ مان }
$$

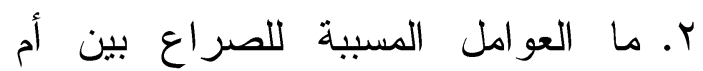

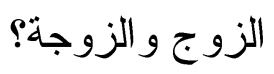

r. ما المشكلات الناجمة عن الصراعلى بين

$$
\text { أم الزوج و الزوجة؟ الزئ }
$$

\section{خامسًا : مفاهيه اللدراسة :}

1- تعريف المشكلة :

تعددت المفاهيم المختلفة حول معني

ضغوط الحياة حيث صيغت تعريفات متعددة،

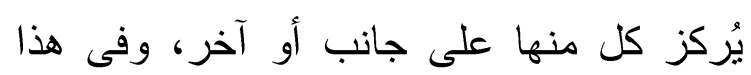
الإطار، ركزت بعض التعريفات على أنه هو" هن البه

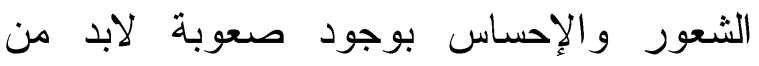
تخطيها، أو عقبة لابد من تجاوزها لتحقيق

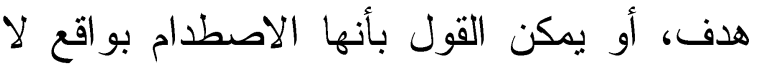

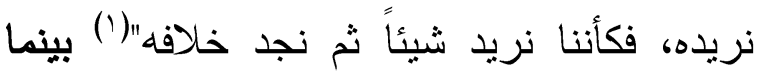
عرفه البعض الآخر على أنه "موقف يو اجه الفرد
و التخخل الزائد من قبل أم الزوج فى حياة ابنها

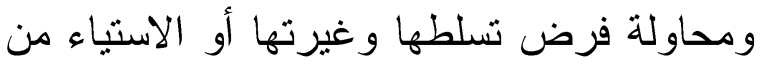
جانب الطرفين مما يجعل الزوج فى حيرة بين

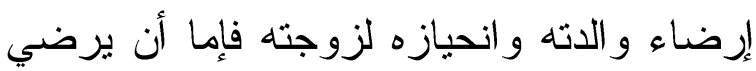
والدته ليرضي لربه وإما أن ينحاز لزوجنه

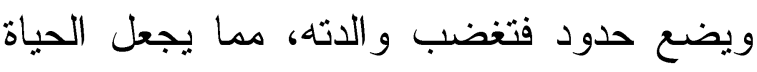
الأسرية للزوجين ملئية بالكثير من المشاكل

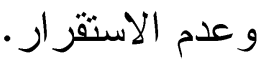
ترتكز الدراسة الراهنة، على المشكلات

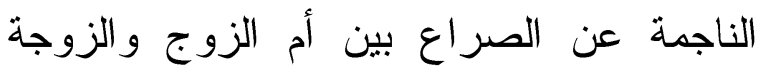

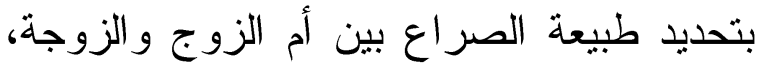
و العوامل المسببة لهذا الصراع، و المشكلات

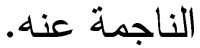

\section{ثانياً : أهمية الدراسة :}

1-تُعد أول دراسة اجتماعية، عن المشكلات

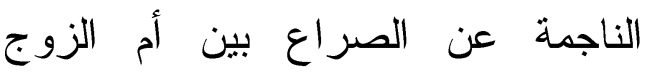
و الزوجة، مطبقة على قرية الخشاشنة بمركز دكرنس بمحافظة الدقهلية، وذلك هُهيه

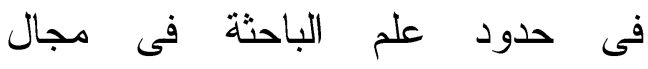
تخصصها.

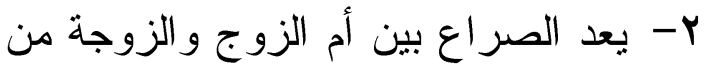

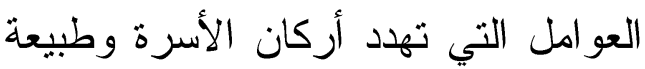
الحياة الزوجية ولما له من تأثير على الهي الجو انب النفسية و الاجتماعية و الاقتصادية و الجنسية للزوجين و وأي تهديد لكيان الاسرة هو تهديد لكيان المجتمع ككل وهو ما أظهرته عديد من الدراسات السابقة. 
عنيف يؤذي به الطرف الآخر لا سيما الزوجة

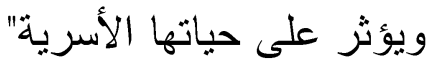

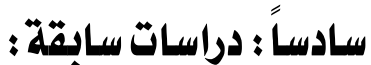

هناك بعض الدراسات المتصلة

بموضوع الدراسة سواء كانت عربية وأجنبية لكنها نتاولت هذا الموضوع من نواحي مختلفة فهناك من ركز على أثر العلاقة بأهل الزوج في ني

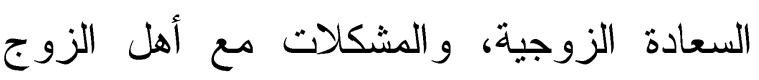
بصفة عامة، وهناك من ركز على العلاقة المعقدة التى تربط الكنة بالحماه، ولم بتطرق أحد

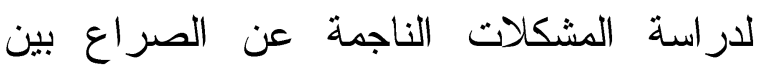

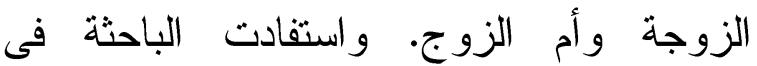
دراستها الر اهنة من هذه الدراسات، و التى تمثل أساسيات البحث فى موضوع المشكلات الناجمة عن الصر اع بين الزوجة وأم الزوج. 1-دراسات تتاولت العلاقة بين الزوجة وأهن الزوجل

$$
\text { الزوج : - الز }
$$

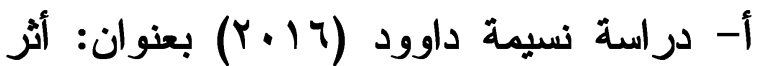
العلاقة بأهل الزوج فى السعادة الزوجية

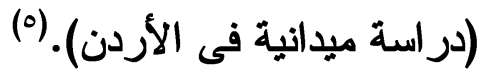

هدفت الدراسة إلى فحص العلاقة بين

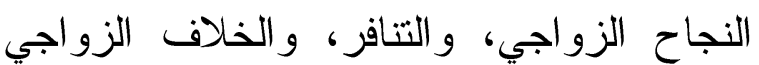
مع أهل الزوج. واستخدمت مجموعة من ولن

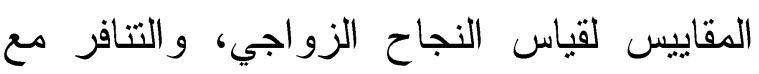

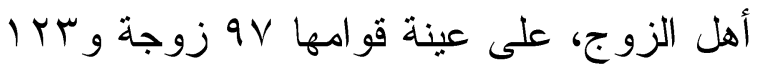
زوجًا ليس بينهم صلة اخيتروا بطريقة كرة

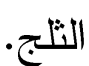

وتوصلت الدراسة لمجموعة من النتائج لعل أبرزها أن هناك علاقة ارتباط موجبة دالة
وتعجز فيه قدراته من مواجهته بفعالية و يعوق

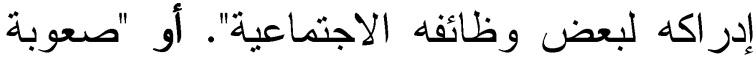
أو غموض أو انحراف عن الموقف الطبيعي يحتاج إلى تفسير و إيجاد الحلول المناسبة

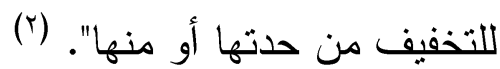
أما البعض الآخر فيري أنه " وجود عائق أمام الطريقة المألوفة و المقبولة و المرغوبة للوصول إلي الأشياء أو الأهداف الاجتماعية،

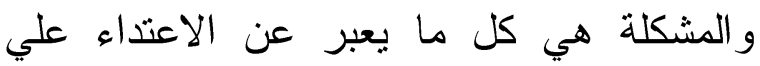
الخير و الجمال والحق، كذللك تعبر المشكلة عن

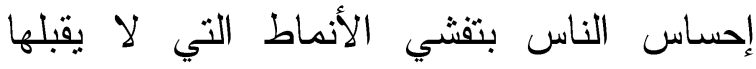
المجتمع ويسلم بها (").

المفهوم الإجرائي للمشكلة :مجموعة من لهن

المعوقات التى تعوق الزوجة لممارسة حياة زوجية هادئة بسبب الاصطدام بالصراعات بين الزوجة

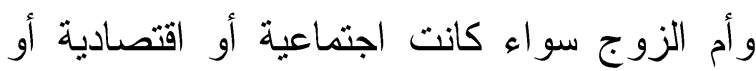
أسرية أو صحية أو نفسية. r-تعريف الصراع :

يعرف الصراع بأنه هو "عملية تفاعل

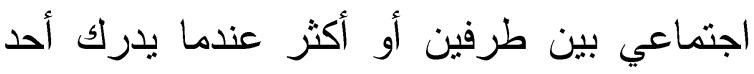
أطر افها أنه يعيق أهدافه مما يخلق لله شعور بالاحباط يقوده الى تفسير طبيعة الموقف

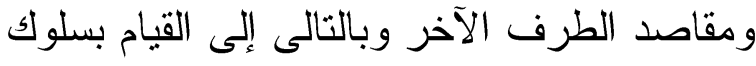

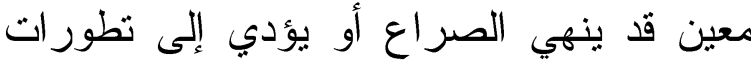

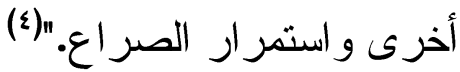
المفهوم الاجرائي للصراع: "هو تفاعل

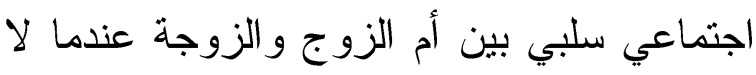
يدرك أي منهما أهدافه مما يجعله يسلك سلوك الك 
فى زواج الأبناء واعتبار ها لهم فى حل الخلافات

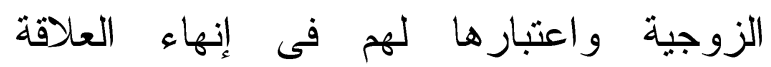

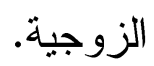

Bryant, C. onger. R .D. \& مراسة Meehan, J. على التغيير فى النجاح الزوجي (Y) هدفت الدراسة لفحص العلاقة بين الخلاف مع أهل الزوج، ونجاح العلاقة الزوجية

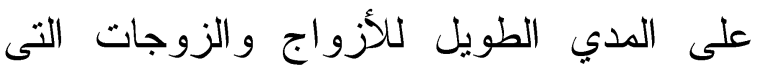
مضي على زواجهم ·r سنة وسطبا. و أظهرت النتائج أن الصراع مع أهل الزوج تضعف

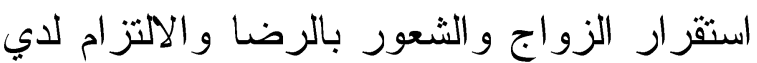
الزوجين مع مرور الزمن.

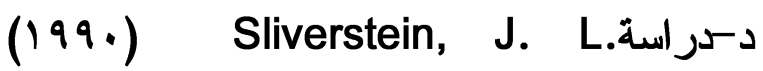
بعنوان:المشكلات مع أهل الزوج. هدفت الدراسة للتعرف على المشكلات

مع أهل الزوج، وأظهرت النتائج أن المشكلات تمثلت فى الغيرة و التتافس و التحويل والإزاحة وعدم وجود حدود فى التعامل والتناقض فى توقعات الدور بين طرفي العلاقة .

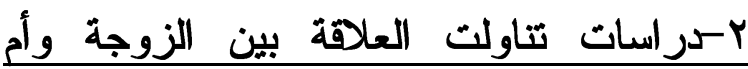
الزوج.

Turner, M. J., Young, C. R., أسرراسة

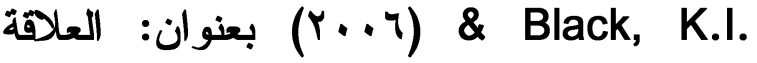

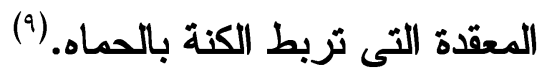

هدفت الدراسة الى التعرف على كيفية إدر الك كل من الزوجة و الحماة لدورها كفرد فى

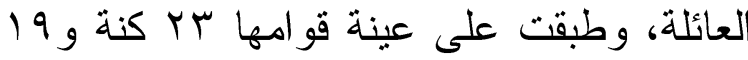
حماه لايرتبطن بصلة، وأظهرت النتائج إلى أنه
احصائيا بين النجاح الزواجي والسعادة بالعلاقة

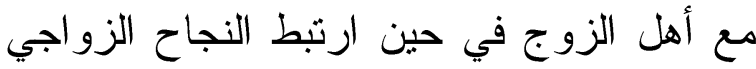

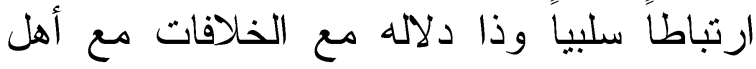

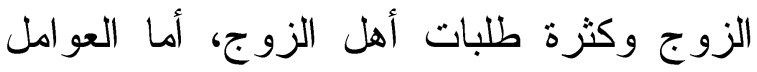

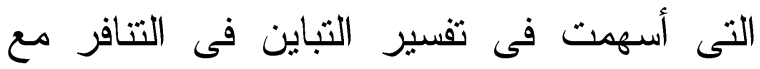

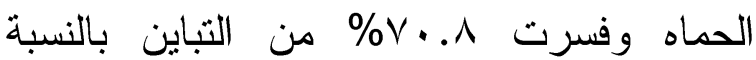
للاككور، و9..٪\% من التباين بالنسبة للإناث،

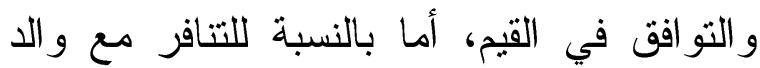
الزوج أو الزوجة فقسرت طبيعة العلاقة معه

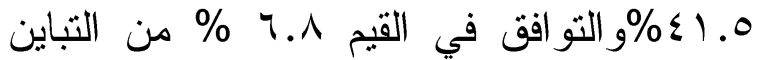

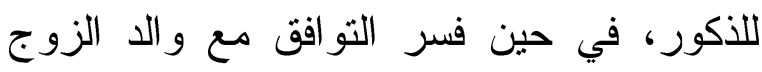
وحده 1 ـ؛ من التباين للإناث.

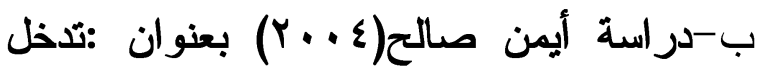

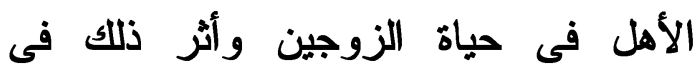

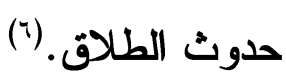

هدفت الدراسة للتعرف على الأسباب التى تؤدي إلى تدخل الأهل فى حياة الأبناء الزوجية، والتعرف على مظاهر اعتبار الثريعه.

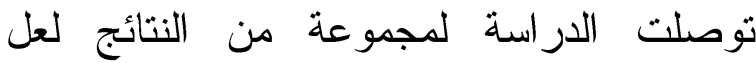
أبرزها تمثلت فى أن أسباب التنخل هي أسباب مباشرة كالغيرة و المال و الخدمة المنزلية والأحفاد وجوداً أو عدماً، والزواج من غير رضأ وضا الأهل

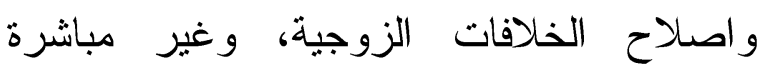
كضعف الوازع الديني و الفقر ووثاقة العلاقة الأسرية و النظرة السائدة للزوجة وحقوقها

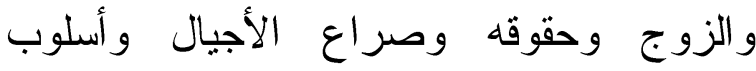
التنشئة الاجتماعية ووسائل الإعلام والزواج المبكر وزواج الاقارب. أما مظاهر اعتبار الشريعه فتمثلت فى اعتبار الشريعه لرضا الأهل الثل 
الصراعات بين أم الزوج والزوجة نظراً لقوة شخصية الزوجة وسيادة كلمتها فى الأسرة بسبب اعتماد أزواجهن عليهن وسناءة أثناء

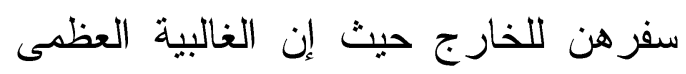
من هذه القرية يسافر عدد كبير من

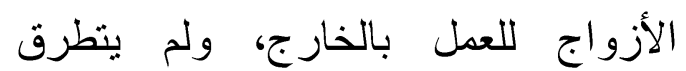
الباحثين لدراسة هذه الظاهرة من قبل.

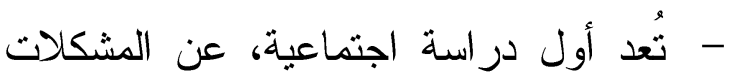

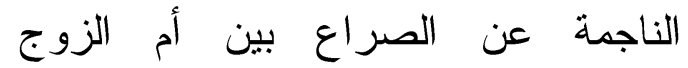
و الزوجة، مطبقة على قرية الخشاشنة بمحافظة الدقهلية، وذلك فى حدود على علم الباحثة فى مجال تخصصها. - خبرة الباحثة، كمرفة لطلاب المعهد العالي

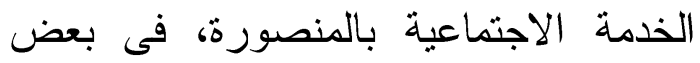

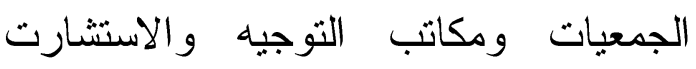
الأسرية التي تعمل على حل المشكلات

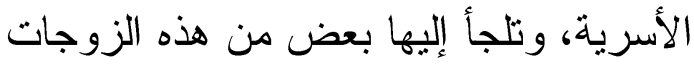
لحل مشكلاتها. حيث سبق أن تعرفت الباحثة

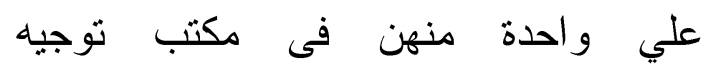
واستثار ات أسرية، كانت تلجأ إليها طلبًا للمساعدة فى مواجهة ما تتعرض له من

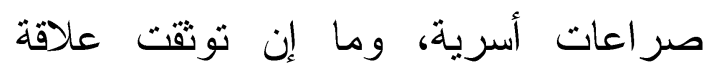

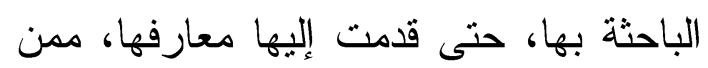
يعانين من نفس المشكلة، وتوطدت صداقة الباحثة بهن جميعاً.

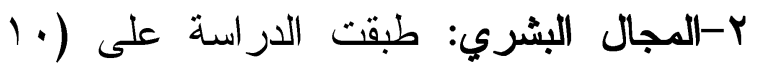

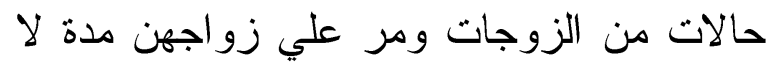
تقل عن سنتين)
يوجد اختلاف فى الإدرالك بين الكنه والحماه،

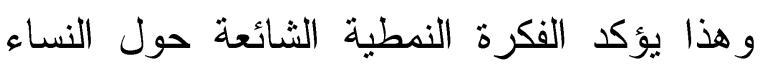
فى هذين الدورين، و أكدت امكانية استفادة النساء

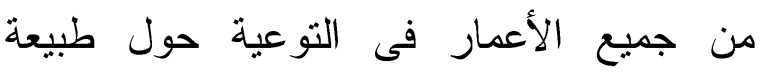

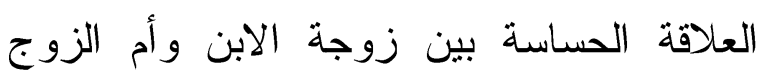

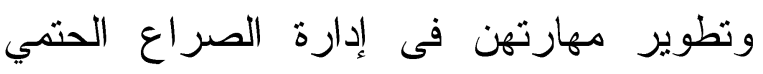
المتضمن فى هذه العلاقة بطريقة مناسبة

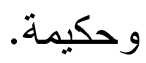

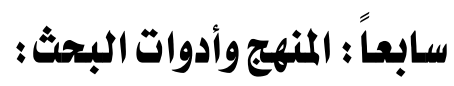
اعتمدت الباحثة فى بحثها الراهن على منهج در اسة الحالة بوصفه منهجاً مناسباً، لطبيعة ألنا

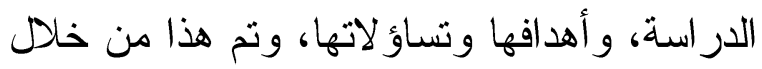

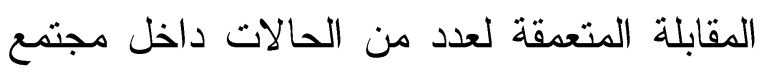

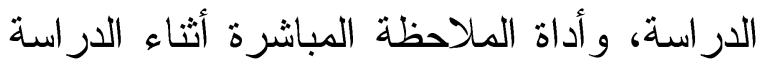

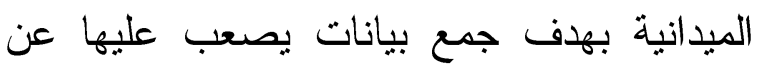
طريق تطبيق دليل دراسة الحالة.

\section{ثامناً : مجالات الدراسة.}

1. المجال الجغرافي: اختارت الباحثة إجراء

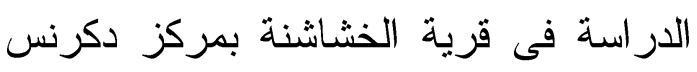
التابعة لمحافظة الدقهلية. وذلك لعدة أسباب: - قرب هذه القرية إلى حد ما من الباحثة،

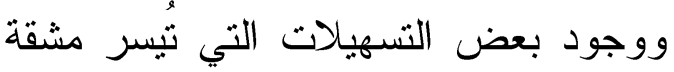
الانتقال والعمل الميداني. وقد يكون هذا

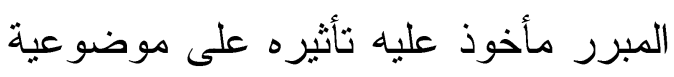

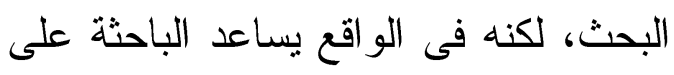
تلافي مشكلات سير الدراسة ودقتها من أبرز ها ما يخص الوقت و الجهد.

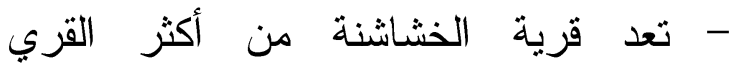

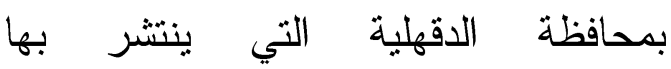




$$
\text { ع- السكن: }
$$

تشير نتائج الدراسة الميدانية أن الصر اعات موجودة عند ساكنى التمليك و الإيجار وفي شقة في بيت الأهل، لكنه يرتقع بين الذين

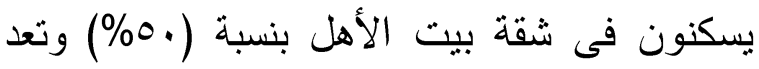

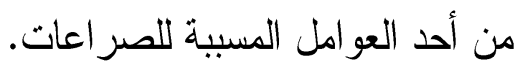
0- عدد سنوات الزواج:

أجمعت حالات الدراسة على أن سنوات اتروات

$$
\text { צ- زوالجهم لم تتعدي عشر سنين. }
$$

تشير نتائج الدراسة الميدانية أن الصــراع موجود بين الذين لديهخ أبناء و الذين ليس لديهر

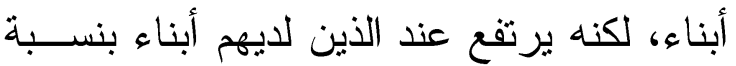

$$
\text { . (\%v•) }
$$

ثانياً : طبيعة الصراعبين الزوجة بوأم الزوج.

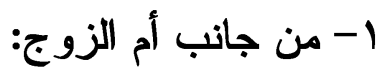
كثفت الدراسة الميدانية الصــر اع مـنـن

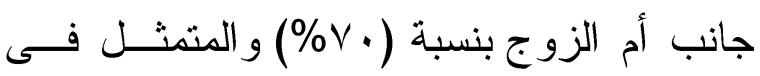

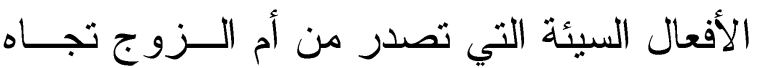
الزوجة و التي تتباين درجة شدتها وتكر ارها. فتقول أحد الزوجات وتعمـلـل دكتــورة

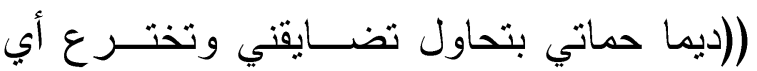
شيء عشان جوزي يزعل مني وتقوله مر اتـلك الك مش معبر اني عشان جوزى مبيحبش بزعلنـى

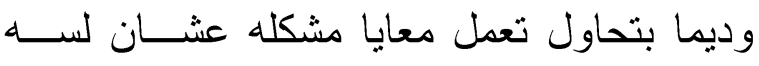

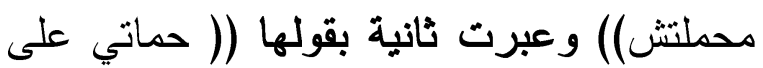
طول بتنككي وبتقول حاجات و الله مبتحصل مني ومش بتزتاح إلا لما يحصل مشكلة وتقعد تزعق

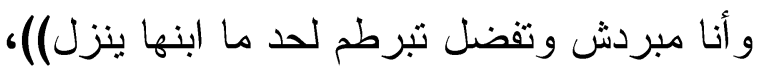

r-المجال الزمني: استغرقت الدراسة الميدانية أربعة أثهر من بداية شهر ابريل حتي نهاية شهر يوليو.

\section{تاسعاً : النتائج التحليلية للدراسة الميدانية؛}

تضمنت الدراسة الميدانية البيانات الأساسية و الخصائص الديموجر افية للمبحوثات، وطبيعة الصراع بين أم الزوج و الزوجة،

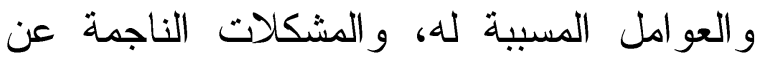
ذللك الصراع، فى إطار دليل العمل الميداني الذي ولي

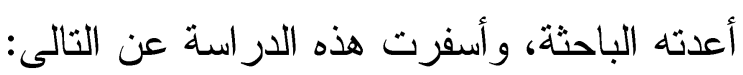

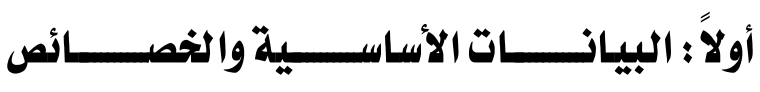

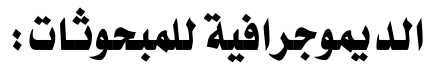

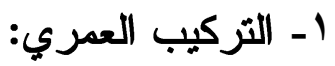
ويقصد به سن كل من الزوجات الـــين

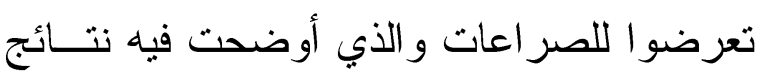

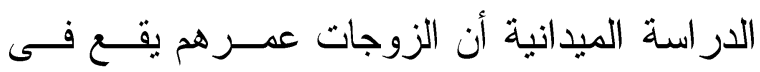
العشرينات وتحت سن العشرين لكنه يرتقع فى سـن العشرين وذلك بنسبة (•^\%).

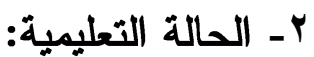
أشارت نتائج الدراسة الميدانية أن هــــه الصر اعات بين أم الزوج و الزوجة موجودة لدي لني

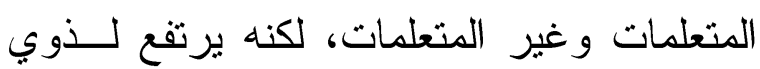

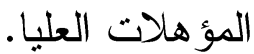
ب- الحالة المهنية: - المولية أوضحت البيانات الأساســية فيهـــا أن النهان

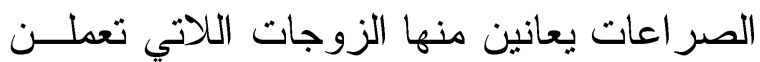

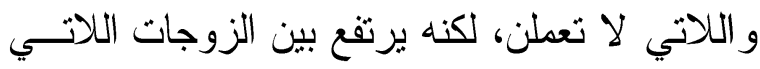

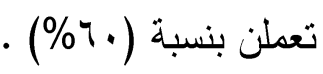


الزوجات ذلك فى حديثها بقولها((إخواته البنات

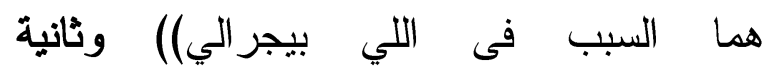
تقول((إخواته البنات ديما قاعدين في البيت يشحنو أمهح بس)) وثالثة تقول (( إخواته البنات

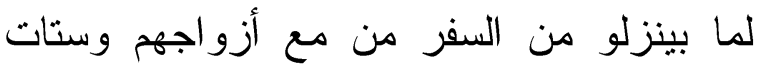
بيوت غيري أنا بشتغل ومش فاضية يقعدوا يسخنوا فى و الدتهم ومسيطرين على تفكيرها مبتميزشي خالص لما بيكونو ا قاعدين معاها))،

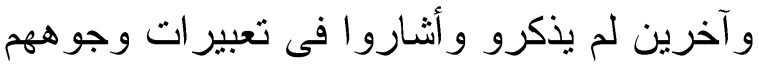
بشدة الاستياء منهن عند استسفسار الباحثة هل له له وله

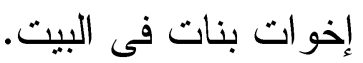

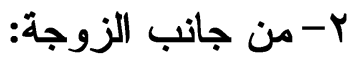

كشفت الدراسة الميدانية أن القلة من الن الصراعات كانت من جانب الزوجة خاصة المتمردة وذلك بنسبة (•r\%) و المتمثلة فى الأفعال السيئة التى تظهر من جانب الزوجة بمحاولة افتعال الصراعات أو عدم تقبل تغيير حياتها بعد الزواج، فذكرت أحد الزوجات بطريقة عنيفة (أنا مبحبش حماتي ومبحبهاش أشات تتذخل فى حياتى لأنها حشرية ونفسي أعيش فى ونى حالى مع جوزي فديماً يحصل مشاكل))، وتثقولي

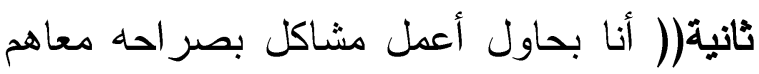
لما ألاقي جوزي بيدلهم فلوس أنا عاوزة أستقل يمكن نطلع من العيلة بس مفيش فايده))، وأخري

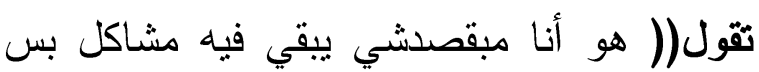

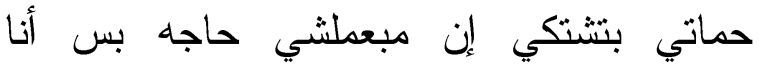
متعودة على وضع معين فى حياتي لما بغيره

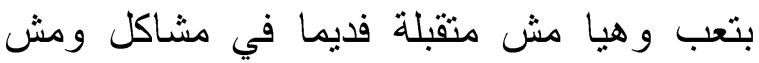

وذكرت ثالثة (( ديمـا بتحسـاول تــدل فـى

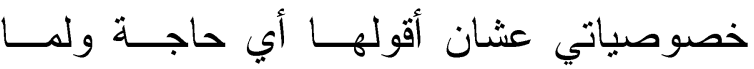
مقولثي شيء تفضل تقول بقي أي كلام يزعـلـ ولما أقول لجوزي وتعرف فتعمل معايا مشكلة))، وفسرت رابعة بقولها((حماتي بعملها كل شـيء وطول اليوم عندها وعلى طول من غير ســبـ قدام بناتها تقعد تشتم وتغلط)). وتسرد خامسة(( بروح لحماتي كل أسبوع ولازم تحاول تضايقني ويوم ما أحكي شيء لجوزي وتجرجره فى الكلام وتعرف لما

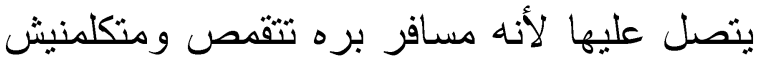

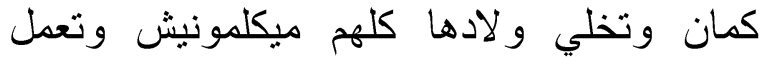

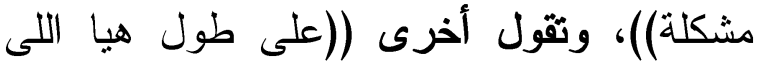
بتعمل مشاكل لما أكون فى شقتي نزلت بدري أشوفها بتعمل إيه اليوم اللى فاضية فيه

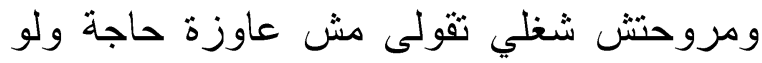
منزلتش تشتكي ولما أقولها ياماما أنزلك امته مش عاوزة حاجة منك وتكبر الدنيا)) تقول أخرى ((على طول فى مشاكل معاها لأن طول ما أنا فى شقتي بتمنع أهلي يجولي يطلعولى وجوزي مش موجود وأي حد مصممة تقطع علاقاتي بيه ولو حاولت أتكلم

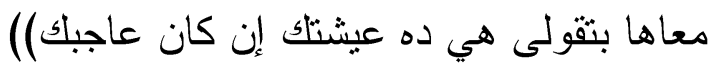

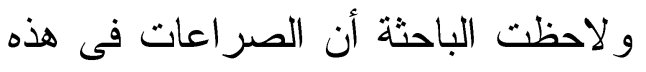
القرية نظراً لسفر الأزواج دائماً و الأبناء

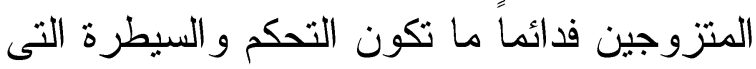
تسبب المشاكل من جانب الأم بنسبة كبيرة، علاوة إذا كان الزوج له إخوات بنات فيقومون

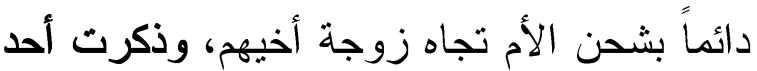


ثانية (( حماتي عاوز اني گ كاعة قاعدة عندها أخدمها ومتحركشي من جنبها هتي عيالى عاوز اني أسبهر و لا أذاكر لهم و لا أكلم حد وأنام كمان عندها كده))، وتحكي ثالثة(( أنا حاسة إن أنا مجرد مرمطون ليها هيا وعيالها ومهما أعمل مبعملشي))، وتسرد رابعة (( حماتى عاوزاني لما أنزل من السفر مع جوزي منقعدشي في شقتي وأنا معايا ب بنات صغيرين عشان أخدم فيها هيا وعيالها وعملت معايا مشكلة واتبلت عليا إن بزعق فيها وبشتمها وتحاول تسمع ابنها وتقوله شوف كل ده عشان قولتلها ثقعد معانا تخدمني أنا و أبوك احنا كبار فى السن))، وتقول خامسة (( حماتى عاوزانى أروح أقعد معاها حتى وجوزي مسافر بتقولي المفروض تقعدى معانا هنا مش مع أهلك وتطبخي وتعملي هنا كل شيء على الرغم من إن بناتها أجوازهم مسافرين وقاعدين عندها وتقولي دي عاداتنا في البلد ولما قولتلها اشمعنه بناتك قاعدين عندك لما هيا عادتكو شدت قصدي وقعدت تزعق وقغدت تشتكى لجوزي في التلفون))، وتحكى أخرى((حماتى كل شوية تيجي تقولى انتي عاوزانا احنا اللي نخدمك ورلا ايه وتثتاكل معايا))، وتشرح أخري((حماتي عاوزانى أدى مرتبي لجوزى ومدخله نفسها بشكل مش حلو جوزي عمره مطلب مني كده وهيا بجحه وتقعد تقولى اديله الفلوس مع أنه مسافر ومبسوط مادياً بس هيا مش عارفة كل خناقاتها يا على الفلوس يا إن أخد أجازة من شغلي عشان أقعد أخدمها دا كل كله كوم و إنها بتعايرني إن لسه مخلفتش)
عاوزة حد يركبني هو أنا مش جاية خدامة

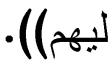
ولاحظت الباحثة أن أم الزوج هي التى

تقوم بكل شيء و الزوجة معتمدة اعتماداً كلياً عليها فى الطعام وتربية الأولاد عليها، حيث تقول أحد الزوجات ((أنا مش فاضية أعمل حاجة خالص ولا فاضية لشكاويها كل شوية من العيال وتصرفاتهح عاوز اهم تخدمهم وهيا ساكته)). كما لاحظت الباحثة عدم حبهم لتحمل مسئولية أنفسهن و أولادهن وعدم وجود تقدير لسن أم أزو اجهن و افتعال الصر اعات.

ثالثاً: العوامل المسببة للصراع بيز أم الزوج والزوجة. أ - العو امل الاجتماعية و الثقافية: أ. ثقافة النظرة السائدة للزوجة: كشفت الدر اسة الميدانيه عن بعض أقو ال الحالات اللاتى يسردن أنهن بالنسبة لأزواجهن مجرد جواري وظيفتهن طاعة والدتهن، مما يؤدي الى تدخل أم الزوج وأيضاً اخواته فى في

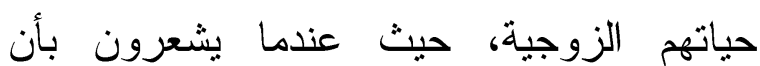
الزوجة قد تجاوزت هذه الوظيفة كأن تكون عاملة وترفض إعطاء المال لزوجها أو تقصر فى خدمة أهل الزوج، وأكدت على ذلك أحد الزوجات بقولها (( أنا حماتى عاوزاني أروح أبيت عندها مش فى شقتي وتمشي كل كلامها عشان تحس إنها مسيطرة على كل ولادها ميقاش حد خرج عن طوعها حتي لو اتدخلت فى خصوصياتي عادي وبتحاول تجبرني على كده ولما رفضت حصل مشكلة كبيرة))، وتسرد 
وتروي أخرى اختلاف عادات الأسرة

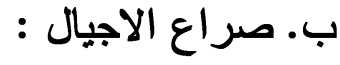

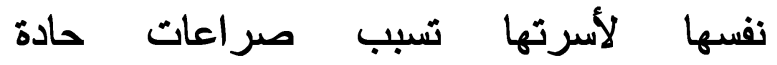
فتقول((حماتى واخدة نسخه من مفاتيح الثقة والأوض وكل شيء ولو قافلة شيء بمفتاح بتيجي من بجاحتها تتشاكل معايا أنا فاض بيه

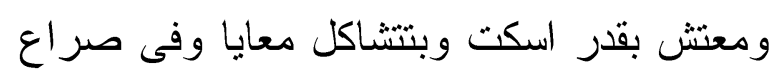

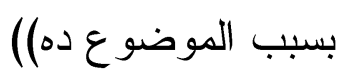

لاحظت الباحثة أن هذا الصراع لا ينشأ

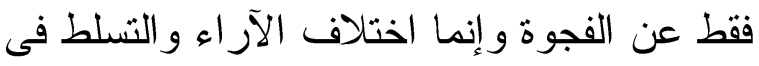
فرض الر أي على حياة زوجات أبناءهن. فهناك

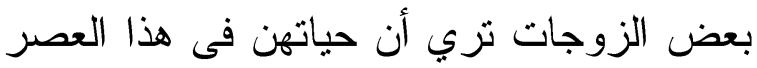
تختلف عن العصر القديم عصر حماو اتهن فترين أنهم يتجاوزن حدودهن وليس عليها تبرير كل شيء أو أخذ الاذن، وتحكي ذلك أحد الزوجات مفسرة ذلك((أنا حياتي بشتري مثلا من على ونى الخدي النت وتجيلي لحد البيت حماتي شايفة إن أنا مضيعه فلوس ابنها فى الفاضي مع إن لما أسافر عشان أشتري الحاجة دي نفس التكلفة بل بهدلة ليه أفهمها إن ده عادي وطبيعي مفيش فبقولها دي خصوصياتي وطريقة حياتي وأنا حرة أنا

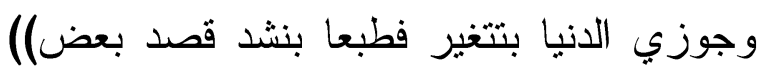

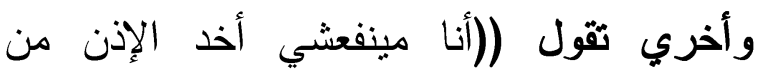
حماتي فى حاجة أنا متجوزي ها ولا لا متجوزة الإدئه جوزي بتزعل لما بقولها كده) أخري تثول

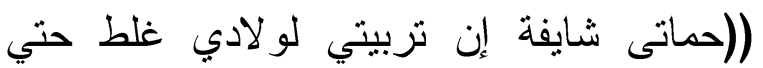
سوري لما بلبسهم بامبرز عاوز اني أحط كو افيل وقماش زي زمان وبتز عل لما أعارضها)).
كثفت الدراسة الميدانيه عن أن اتساع

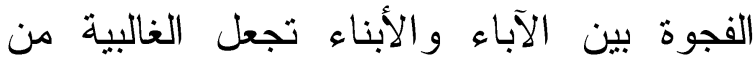
الأبناء لا تنتبه لفرض أعرافهم و وأفكارهم ونظراتهم حتى المتزوجين، فغالباً ما يحدث الأه اختلاف فى وجهات النظر تتشأ بين الزوجة وأم الزوج فتأخذ ذلك على محمل عدم التقدير، وأكدت أحد الزوجات على ذلك بقولها ((أنا لو عاوزة أعمل حاجه فى شقتي أنا وجوزي لو مقولناش لحماتي وحمايا بيحصل مشاكل))، وتحكي ثانية ((حماتي تقعد تقولى إنتي مبتقدريش

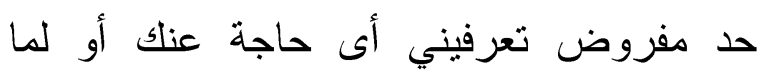

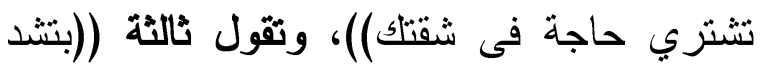
قصدي على طول بسبب مناسبات وتقولى إزاي الي تروحي مع أهلك من غيري أنا اللى أجي معاكي عشان جوزك مش هنا وأنا مش مثقبلة الكلام منها لأن أنا قاعدة مع أهلى و الناس بتيجي تعزني وبتعزم أهلى وساعات هيا مش بتكون معزومة))، وتحكي رابعه(( أنا وجوزى لهئ ديما لهيا

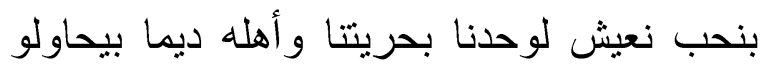
يتذخلو وديما حماتى تحاول تفتعل معايا أي لتوحني مشكله وتقعد تقولي إنتي مبتفهيش فى الأصول إزاي تروحي انتي وجوزك عند أهلك من غير متقولي))، وتسرد خامسة ((على طول حماتى لما نتتاقش فى موضوع و احنا قاعدين واختلف معاها

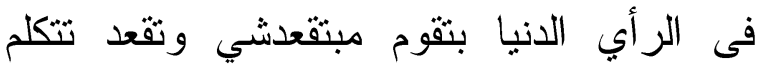
بتزيقة))، وتحكى سادسة ((انا لو طلعت شقتي لوني

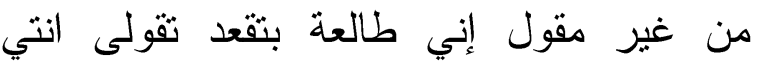

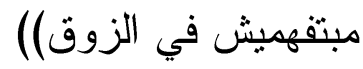


دكتور و اللى رئيس جامعة حماتي بقي كل متتكلم

ج. التششئة الاجتماعية :

معايا انتي فلاحة إحنا ناس راقية وحاجة تانية تختلف كل أسرة فى طبيعة العلاقات بين

مع أنا عارفة أصلهم وفصلهم وهما اللى أفر ادها، فهناك من الأسر تكون علاقاتهم مفتوحة بيستعروا وبيتمنظروا بناس مش تقربلهم ولا بيطقوهم) د. وسائل الاعلام والتواصل الاجتماعي

كثفت الدراسة الميدانيه عن وسائل

الاعلام كالأفلام و المسلسلات غالباً ما تعطي تصور إما نموذجياً من الرومانسية والغر ام بين الزوجين قبل الزواج وبعده والحماه قد تكون غير موجودة أو مكر بين الزوجة وأم الزوج، حيث تتخذ زوجة الإبن عدوة لأن يثبت لها غير ذلك، وتؤكد على ذلك أحد الزوجات ((حماتي من يوم مدخلت بتعاملني كإنى عدوتها وبتحرص مني فى كل شيء وحصل موقف بثقولى ده انتي طعلتي غير مكنت فكر اكي وحشة أوي استغربت))، وثانية تقول ((حماتي تقعد تدي أمثال شعبية طول مهي قاعدة عن علاقة الزوجة بحماتها وتقولى فى المسلسل شوفتي مرات ابنها عملت ايه وتقعد تشتم كلهم كده قولتلها ليه بنتك كده مسكنا فى بعض وشتمتني))، وتسرد ثالثة () تقعد تقول لبنتها وتلقح عليه شوفي مرات الابن فى التمثيلية عاملة ازاي وبنتها تقولها هيا فى التمثيلات بس تقولها عندك حق وفى الحقيقة وحياتك دي حاجة تقرف وتقعد تستفز فيه)). كما أوضحت أيضا أن وسائل التواصل الاجتماعي أيضاً لها دور كبير، حيث ذكرث أحد الزوجات ((النت ده سبب فى مشاكل كثيره بيني وبين حماتي وصلت لدرجة إنى لما بشير بوست لا يتحتفظون بالخصوصية ويرون أن كل شيء عادي مكثوفة ومشتركة، وأسر أخري تكون الحدود شيء أساسي في العلاقات، فكلاً من ومن أفر ادها المتزوجين يحتفظ بخصوصيته، وأكدت أحد الزوجات على ذلك بقولها((أنا أهل جوزي ديما كل حاجة عاوزين يعرفو ها كبيرة وصغيرة وبيحاولو بجميع الطرق ومفتوحين على بعض بشكل بيخليني أتضايق أنا كنت فى بيت أهلى غير كده أخويا ومراته محدش يعرف عنهم حاجة وعن خصوصياتهم ولا أبويا و لا أمي كل واحد فى حاله ونتجمع فى المناسبات، دول لا عمال على بطال عاوزين لمه وللك ويعرفوا كل شيء وده بيجيب مشاكل)|. وثقول ثانية (( حماتى وأهله بيسمحوا لنفسهم يتذخلو فى كل شيء مش بس بيني وبين جوزي لا بيتعدوا حدودهم في انتقاد أهلى وخاصةً أختي وعاوزين كل شيء يعرفوه مهما كان وبتدي لنفسها الحق إنها نتذخل بينا)( وتثول ثالثة مشيرة إلى فرق المستوي الاجتماعي فى التششئة(( أنا عيلتي حاجة وأهل جوزي حاجة تانية عننا، جوزي كان شغال فى فرن مع أبوه وبيطلع بيبع عيش على الأسوار وعشان يخرجو من الدايرة دي باعو الفرن واشتروا عمارة وكأنهخ اشتروا حاجة مش عند حد إنما أهلى كلهم مر اكز ومستويات اللى ضنابط و اللى مستشار و اللى لو اء و اللى مهندس و اللى 


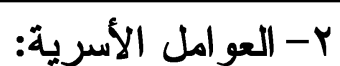

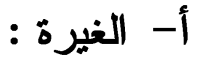

كثفت الدراسة الميدانيه عن الغيرة كأحد

العو امل المسببة و التى ترفضه الطبيعة الانسانية

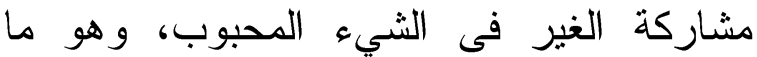

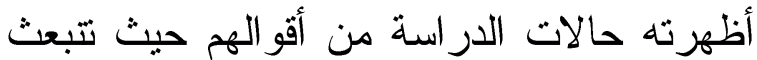
الغيرة فى قلب الأم بسبب اهتمام الزوج بالزوجها

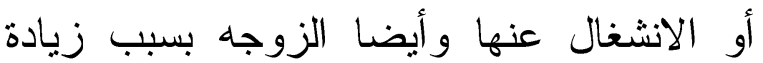
حب الزوج لأمه ومقارنته لها، فيحدث افتعال

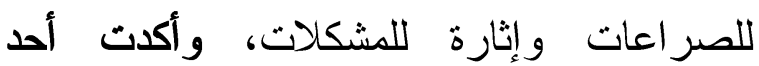

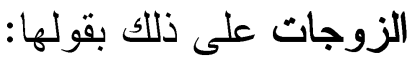

(حماتي بتغير مني بشكل غير طبيعي

حتي لو طبخت فى شقتي من غيرتها تحاول تعمل أكل وتطلعهولنا وهو قايلها هاكل فوق مع فين فئن مراتي)) وتقول ثانية ((حماتي بتغير لو دخلت أكلم جوزي فى التلفون هو مسافر وبيكلمني بليل تيليه بعد مبيخلص شغل بتقعد تزعق لو لقيته رن عليه))، وتحكي ثالثة (( حماتي من غيرتها عيزاني أنا وجوزي ننزل ننام عندها تحت ونسيب شقتنا وناكل عندها ديما ومنتلمشي على

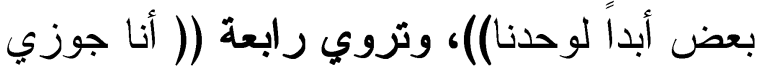
سبب الغيرة اللى بينا لأنه مش عنده حسن تصرف للأمور وبيخليني أغير من أمه لما يقلل مني ويفرد نفسه بالكلام ولما بروح لأمه يقعد يترسم بالكلام بيخلى أمه الغيرة تزيد في قلبها

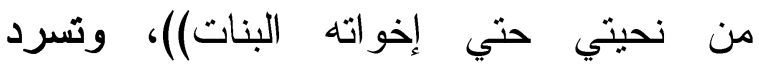
خامسه((أنا حماتى بتغير لو جوزي جيه قعد جمبي أو قعدت جمبه تحت عندها تحاول تخترع حاجة عشان متخلناش نقعد مع بعض أو تمسكنا
على الفيس حماتى بتاخده لنفسها وتقعد تتشاكل معايا جوزي مبيعملثي كده))، وبثانية تحكي((حماتي لو قاعدة جنبها فى أى مكان وجيت أكلم حد أو حتي جوزي تقعد تبص فى لئ الكلام أقولها فيه إيه با ماما تقولى انتي بتر اسلي مين وابني مش موجود مع إن بكلم جوزي لأنه مسافر بره فبيكلمني و اتس)). وتشرح ثالثة((أنا كل ما أقعد على النت فئت تدخل على الخاص تقولى بتعملي ايه وبتكلمى مين مع إن أنا ممكن عشان الواي فاي الماسنجر لفارئر بيبقي باين إنه مفتوح وأنا ببقي نايمة عشان شغلي الصبح فبضطر اتصل عليها الصبح اقولها انتي بعتالى ايه وحتي لو فاتحة وبكلم حد حضرتك عاوزة ايه لدرجة إن قولتلها انا متجوزة مين بالضبط))، وتقول رابعة ((أنا لما أكون مخنوقة من حماتي بستفزها على النت الت التهورة التهائ وبحسبن عليها وولادها طبعا بيروحو يقوللها عشان هيا معهاش فيس))، وتحكي خامسة (ر) حماتي بتخلى و لادها لما يكون فيه مشكلة بينا يقعدو يلقحو ويكتبو كلام وحش عليه على الفيس

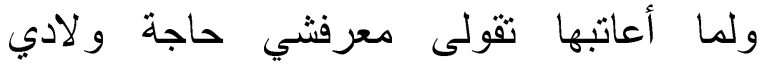
ميعملوش كده أقولها ودي إيه مترضاش تبص تقولى انتي سمعتي بقولك إيه و أنا بسمعها وهيا بتكلمه وبتقول لهم اعملو كذا قولتلها حرام عليكي))، وتقول أخري ((حماتى بتذخل فى دماغ جوزي إن بكلم ناس على النت وكل يوم

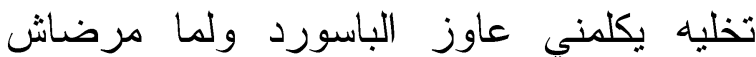
أدهوله تكلمني تتشاكل معايا)) 
وتروي ثالثة (( أنا بعمل فى شقتي أكل

وأنزله لها مثلا لما أطبخ أي شيء تقعد تقولى الى بعلى تعالى اطبخي هنا اعملى اللى هتعمليه هنا أقولها أنا مبعرفشي أطبخ إلا فى شقتي براحتي تزعل وتتقص))، وتحكي رابعة ((كل ما أطبخ حاجة

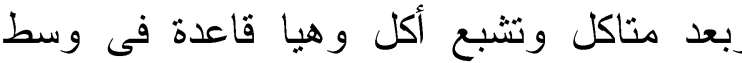
و لادها تقعد تتزيق على الأكل وتقولي نفسي أكل أكله حلوة أنا باكل عكاد))، وتسرد خامسة ((أنا ببقي فى شغلى وبرجع متأخر وجوزي مسافر

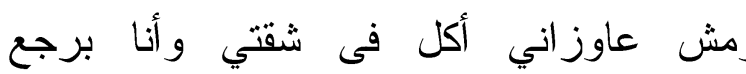
المغرب وتقعد تقولى عادي وبتحرج وساعات

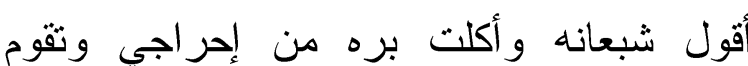
واحنا قاعدين تقول بتيجو تاكلو على الجاهز وتقعد تستفز فيه بالكلام)).

وتروي أخري((أنا بحكم شغلي مقدش بأن

أخدم حماتي طول اليوم وهيا على طول تشتكي أنا طول اليوم في شغلي وأجي بحاول أساعدها بس هيا مبتقدرشي تعبي طول اليوم ولو جوزي اتكلم بتروح تسخن حمايا عليه عشان تعمل معايا

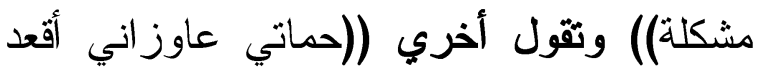
لللساعة واحدة بليل لحد مسيادتها تتام و أخدم فيها هيا وبناتها وصبيانها فبتقعد بقي تتشاكل معايا على طول))،وتحكي أخرى((صحيح أنا سبب فى لهى المشاكل بس عمري مهنزل اطبخلها وهيا صحتها حلوة هيا بتزعل ان مبنزلشي اطبخ

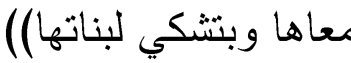

في بعض))، وتروي أخرى(( أنا حماتي الغيرة بتموتها لما تلاقي جوزي وهو راجع من السفر هياكل معايا لوحدنا فوق وتحاول تاكله بأي شكل هن وهو بيحاول يتحجج بأي شيء ولو حست إنه جابلي حاجة تقعد تقوله انته بتخلص فلوسك على تفاهات لم نفسك ولم قرشك عشان تعمل مستقبل ليك ولعيالك ولما يطلعلها اللى جايبه ليها تقوله بتستخسر فيه هو ده اللى جبته))، وتدكي أخري على خلاف السابقات ((أنا بضايق لما ألاقيه

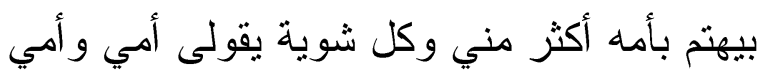

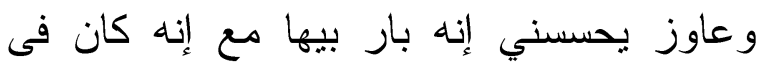
الأول يقعد يزعق فيها و أنا كنت أقوله عيب بس بل بـ بـان أنا عدت بحس بغيرة لأن هيا أكثر منه عاوزة تحسني بكده وبتقعد تضايق فيه وبتموت لو لو لونان

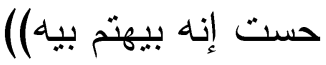
ب-الخدمة المنزلية

كثفت الدراسة الميدانيه عن أن الن الزوجات النى يعشن مع أهل الزوج فى بيت

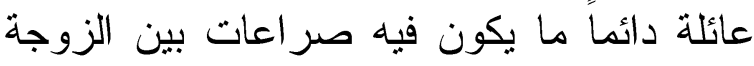

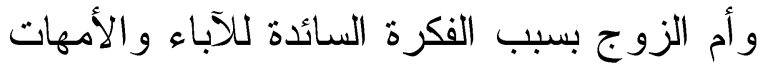
أن المفروض على الزوجه أن تقوم بخدمنهم

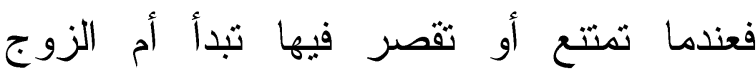

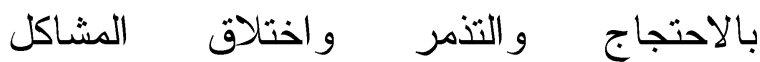
و الصراعات وهو ما أكدت عليه أحد الزوجات بقولها(( أنا مهما أعمل أكل لازم تطلعلي فيه

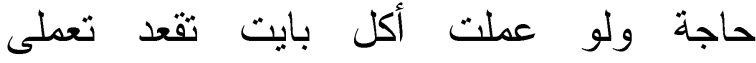

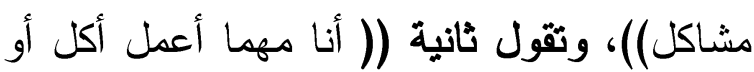
أنظف ترجع تقولى انتى بتعمليلي إيه وتقعد تقول

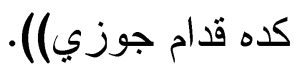


متجوزية جوزي طبيعي إن أطلب منه تقولى كل

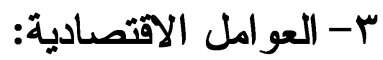
فلوسه معايا ولما هيديكي هيديكي بأمر مني)).

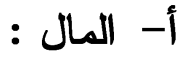
و لاحظت الباحثة أن ذلك بسبب سفر هنائ الزوج واعتماده أهله فى إدخار فلوسه و انفاقه

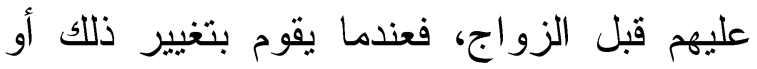

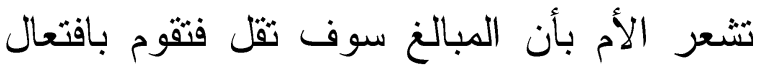

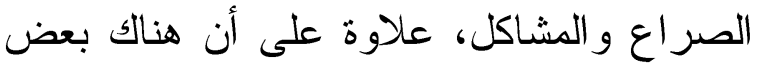
الحموات من شدة تسلطهن وخوفهن من أن الزوجة تأخد من زوجها شيء خاصة لو كانت

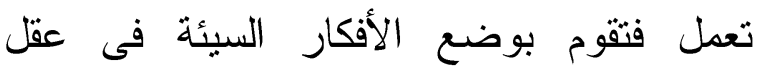

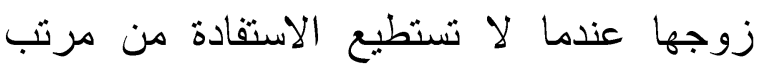

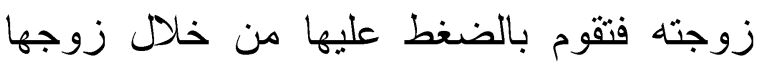
لكي تترك عملها أو يصبح هذا المال محل بلان صر اع وتؤكد ذلك أحد لزوجات بقولها ((حماتى

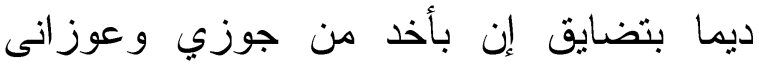

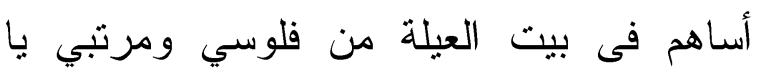
أسيب الثغل)) وثانية نقول ((حماتي مخليه جوزي كل يوم يقولى سيبي شغلك أنا مش جايلي

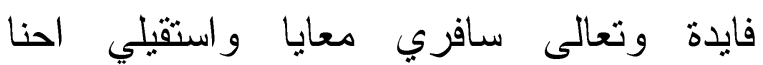
مستفدين ايه أمي حتي بتقولى انك كنتي بشتكي

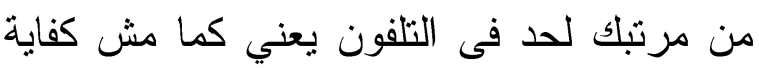
اللى بتعمله بتتسنط عليه و أنا بكلم أمى أنا بكمل بكل فئل

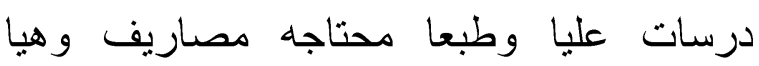
خايفة إن أطلب من جوزي))، وتشير أخري أنها

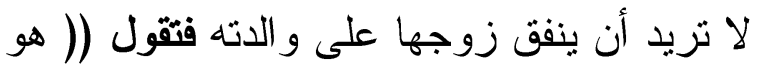
يديلهم ليه هما مش محتاجين ولاده أولى)) وأخري نقول (مفروض يصرف على مراته وعياله بس ليها جوز ها يصرف عليها هيا عاوزه تاخد فلوسه)).

كثفت الدراسة الميدانية عن أن المال

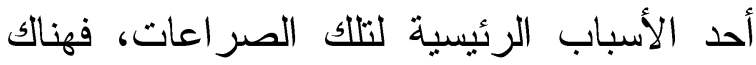
أبوان معتمدين مادياً ولو جزئياً على الإبن الإني

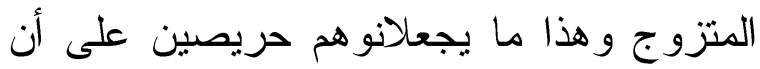
لا يذهب المال هنا أو هناك أو يقل نصيبهم منه هندئ بشكل أو آخر وعندما تحاول الزوجة التنتع بمال زوجها وأخذ حقوقها هنالك إذا كان الزوج غنياً فيصبح المال محل تتافس وتجاذب فتبدأ الأم تراقب التصرفات المادية للزوج تجاه زوجته ثم

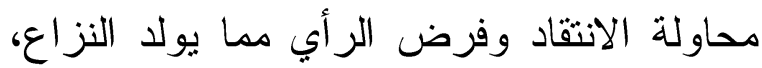
وأكدت أحد الزوجات على ذلك بقولها((حماتي على طول مش عاوزاني أطلب من جوزي فلوس وتقولى تطلبيها مني وتعرفيني ليه وهو موني يبعتلى أنا ميبعتلكيش و أنا مبو افقشي على ونى كدئ لئه فبيحصل مشاكل)) ، وثثانية نقول ((هو حاطط كل فلوسه مع و الدته ولما بتعرف إنه بيبعتلى

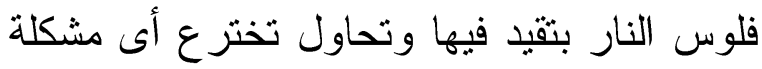
بيني وبينها وتزعله مني عشان ميدينيش فلوس)).

وثالثة تحكي((حماتى كل متعرف إن خدت فلوس من جوزي تقولى انتي مش بتشتغلي بتودي فلوسك فين وبنشد قصد بعض جند) وتنقول رابعة ((حماتى مش عاوزة جوزي يبعت فلوس غير ليها ولبناتها إنما أنا وو لاده لا))، وتسرد

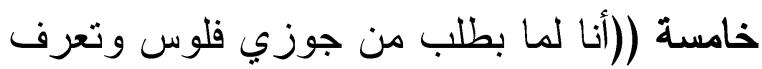
بتعمل معايا مشكلة وتقولى أنا قولتلك لما تعوزي لتوني اطلبي مني أنا فبقولها أنا مش متجوز اكي أنا 
جوزي رافع عليه قضيه طاعة فحاولت أعمـلـ طعن قالولي هيترفض وروحت لمحامي عشَــان يرفعلي قضية طلاق ولما رفع قضــية الطــاق زوجي طلقني قبل المحكمــة تحكــم بــالطلاق ومرضاش يرجعلي حاجة غير النفقة و لا قائمسـة و لا مؤخر)). و أكدت زوجه ثانية على هذا بقولها (( العلاقات بيننا اضطربت حتى وصلت لمرحلة رفع دعوى طلاق)) ،وتؤكد ثالثة حيث تم ردها (كثر المشاكل وعدم قدرة جوزي إن ميزعلشي أمه قالتله طلقني فطلقني وردني من غير معرف عشان حلفان أمه بس طبعا حصل شرخ كبيـر

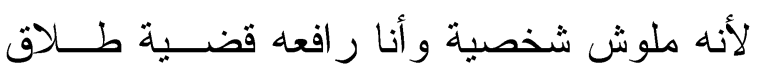

$$
\text { بسبب الصر اعات دي) }
$$

ب-التنمر العائلي ضد الزوجة: أظهرت الدراسة وجود بعض لأشــكال التنمر من جانب أهل الزوج جميعاً عند حـدوث

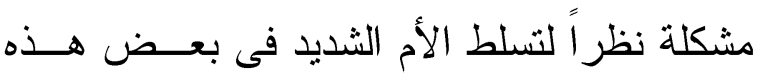
الأسر وتؤكد على ذلك أحد الزوجات بقولها(( أنا لما زعلت مع حماتى و هانتتي على الرغم من إن معملتش حاجة فيها اقسم بالله ومرديـــت علــى اسائتها الا أنا كنت بعاني من تتمر مــن أهـلـل جوزي كله حتي ســالايفي واخواتــه الرجالـــة و البنات))، وتحكي ثانية(( لما بيحصل مشكلة مع حماتى ولادها كلهم بيقعدو يلقحو عليـهـ علــى الفيس))، وتحكي ثالثة ((لما بيحصــل مشــــلة و لادها وجوز ها بيــــلو بيســتخلو إن جــوزي مسافر وبيهدلوني وبيشــتوني وبيطردونــي)(ا)، وتشرد رابعة (لو اتخانقت مع حماتى كله بيعمل زي الروبطية حتي جوزي نفسه يقعـد يقــــلى
رابعاً: المشكلات النساجمة عن الصراع بيز أم الززوج

والزوجهة:

1-مشكلات اجتماعية : أ. التفكك الاسري

أظهرت الدراسة الميدانيــة أن الغالبيـــة تعرضوا للتفكك الأسري النفسـي باضـــر اب

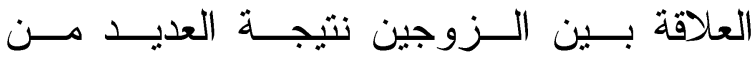
الصر اعات، وتحكي أحد الزوجات موضحة ذلك بقولها (( جوزي بيقولي و الله " عبرت المبحوثة بالفاظ لا تسنطيع الباحثة ذكرها" لمتجوز عليكي وهخدها فى هي شقة بره و أعيش حياتي وسايبك مع أمي تذل فيك ومش هطلقك بدل مش بتسمعي كلامها))، وثانية تحكي ((بيحلف عليه لو خرجت بسبب المشاكل

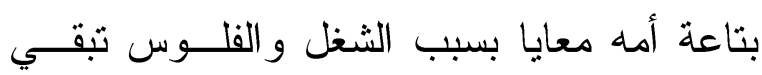
محرمة عليه))، وأخــرى تشــرد ((مــن كثـر

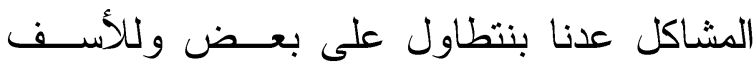
أساسها مش مشكله بينا كله بسبب أمه))، وثروي أخري ((وصلت الدرجة بجوزي إنه مد إيده عليه

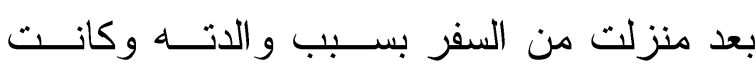
مبسوطة واستتجدت بأهلى جم خدوني وخد مني العيال))، وتقول أخري((أنا جوزي كل مينـزل من السفر أمه تيجي تقعدلي في الثــقه وتعدـلـل

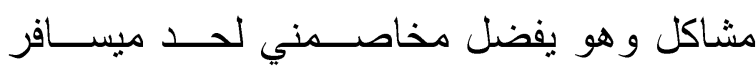
وساعات يسافر وهو مبيكلمنيش وساعة ميسافر هيا تمشي) أما البعض الآخــر أجمعـــوا علــى أن أسر هم تعرضت للتفكــــ الأســري القــانوني والمتمثل في حدوث حالات الطلاق.وتعبر أحد الزوجات عن ذلك بقولها ((بعد شهرين لقيــت 
معلثي ولما ينزل بيقي أوسخ منهم))، وتقـول أهل جوزي حصل مشكلة أكبر ومعدوش العيلنتين

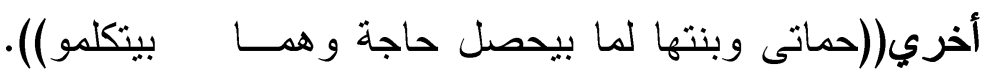

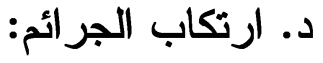

كثفت الدراسة الميدانية عـنـن ارتكــاب

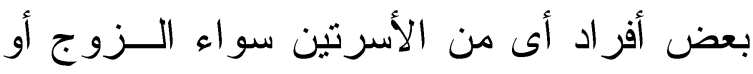

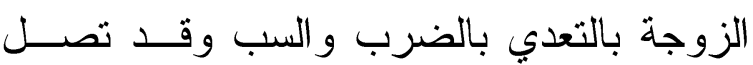

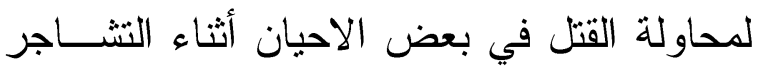

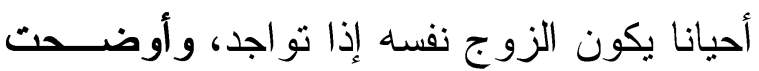

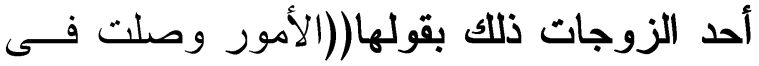
الصر اعات دي بين وبين حماتى وتدخل أو لادها

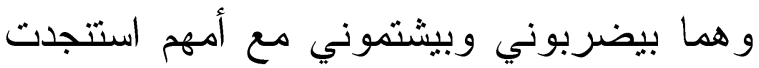
بأهلى لأن جوزي مسافر أخويا لها شافني بتبهدل لقيته رفع مطواه وعور أخو جوزي لما لقاه بيمد ايده عليه وبيجرو ور ايا))، وتقول ثانية ((حماتى

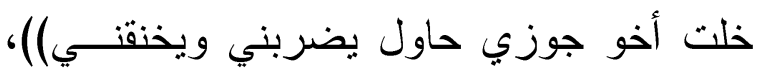
وتقول ثالثة((أنا عمري متخيلت إن أهل جوزي

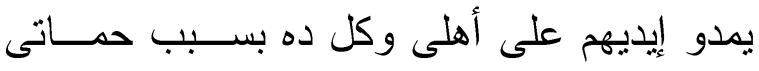
قاعدة تقولهم اضربو هم وارموهم بره في الثارع

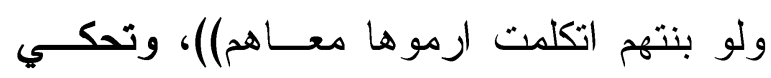

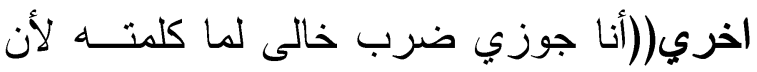
بابايا منوفي) (التري ه- التهديد بزواج من أخرى: كثفت الدراسة الميدانية عـن تعـرض برض

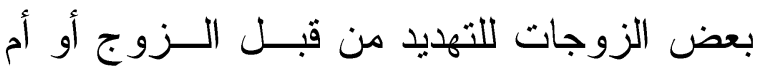

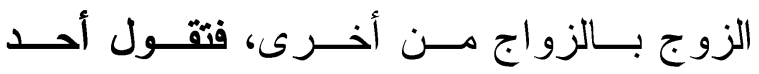
الزوجات(( جوزي لما حصل خلاف مع حماتى أول منزلت من السفر خد مني العيال وبيهددني

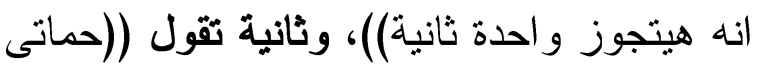

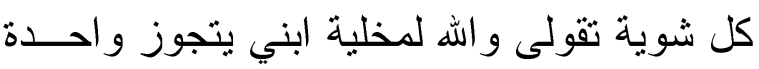

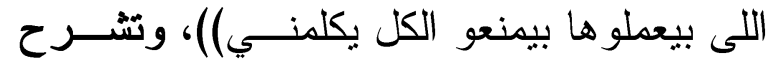

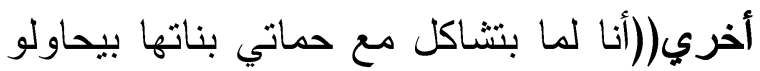

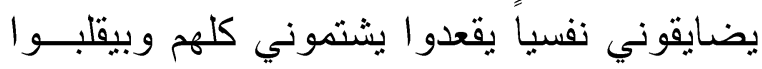
جوزي وبيخلوه يعمل زيهم)|). ج. ضعف الروابط العائلية بين أسرتي الــزورج

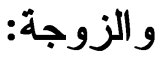
كثفت الدراسة عن أن الصرعات بين أم الزوج و الزوجة جعلت هناك صــر اعات بــين العائلتين حيث عندما يعلم أهل الزوجة بالمعاملة السيئة لابنته فقد تحدث فى بعض الاحيان بعض

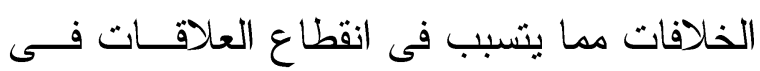

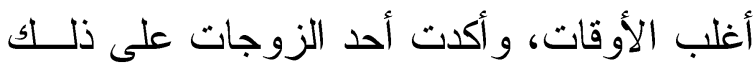
بقولها((أنا حماتى خلت جوزي واخو اته يقاطعو

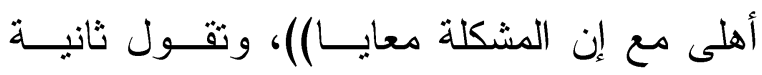

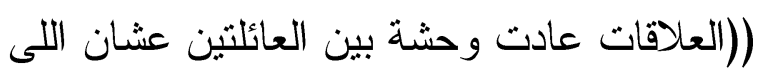
اتعرضتله من حماتي اهلى زعلانين وجــوزي لهاني

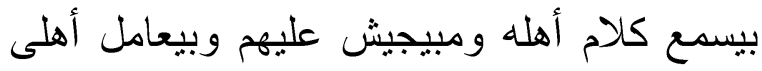

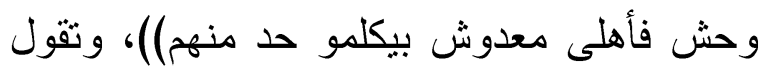

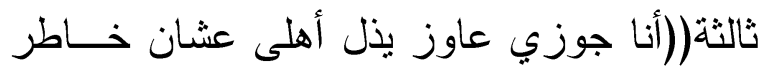
أمه بتقوله لازم يجو يتذلولى ويبوسوا جذمتي))،

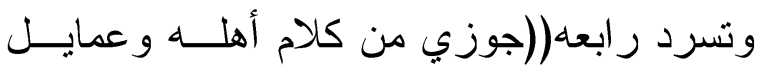
حماتى وأهله نفسه بيتطاولو على أهلى بالســـبـ

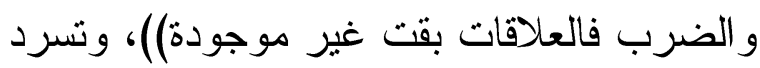

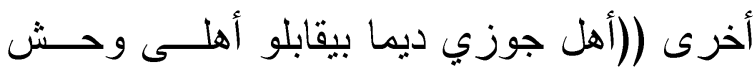

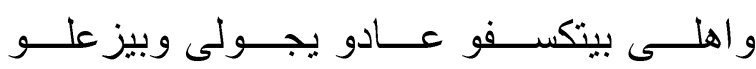

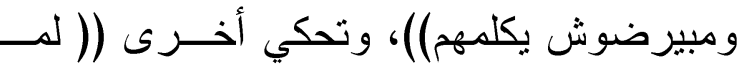

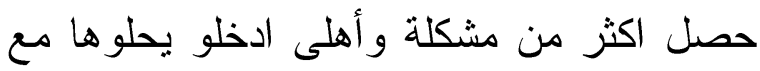


بقيت مكتئبة علي طول وبحس إن ضربات قلبي

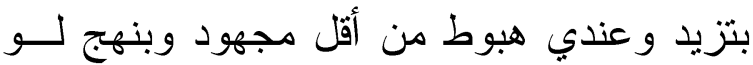
مشيت أو اتحركت خطوتين وسناني زى اللــي بتكهرب ورجلي مش شيلاني و لا بقـدر أقــف

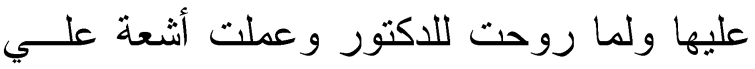
القلب وملقتشي حاجة في القلب قالي روحي لحد نفسية وعصبية فلما ذهبــت لــكتورة نفســية وحكيت ليها الأعر اض قالتلي انتي عندك مشاكل

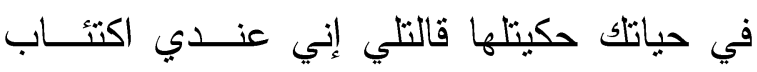
وبتعالج منه)) بينما ذكرت زوجة ثانية النية أنها تشعر بالاحباط ((المشكلة إني لما عاد بيحصل شـــيء زئه

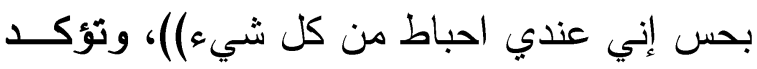
ثانية((بحس أني محبطة وكار هه نفسي من كثر انتقاد حماتى ليه)). وتسرد أخريات مدي شعور هن بــالتوتر فنتقول زوجة ((بصر احة معتش بقدر أتحكم فــي

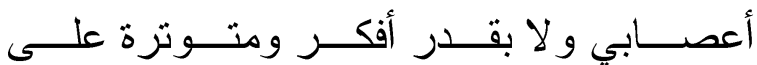

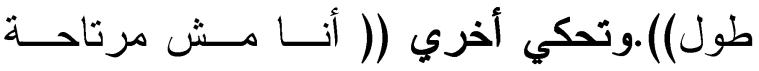
وحياتي عايشها في قلق وتوتر على طول)). بينما تحكي زوجات أخري عن تضررها

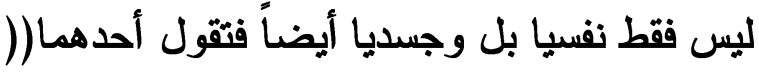
أنا من كثر المشاكل دايما بشعر بصداع مستمر

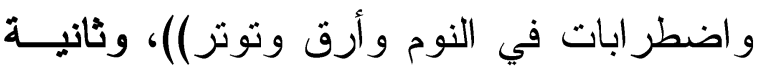
تقول ((أنا حالتي النفسية بقت وحشة ومن كثر تفكيري في المشاكل دي وقلقي مكنتش بعـرف

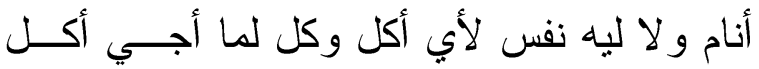
حاجة ارجع فأخويا خدني كثف عليه الـــكتور قاله القولون عصبي))، وتحكي ثالثة( (ووصــلت الته

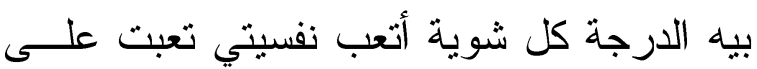

ثانية انا معتش عاوز اكي فى بيتـي))، وتقــول أخري((انا هخلى ابني يتجوز واحدة بتخلفله)) و. الخيانة الزوجية كثفت الدراسة الميدانية عن خيانة بعض المض الأزو اج لزواجاتهن حيث قالت أحد الزوجــات (أنا شوفت جوزي بيخوني فى التلفون وعلى لرونى

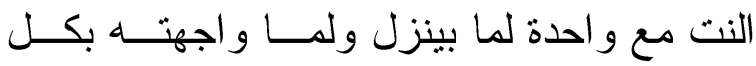

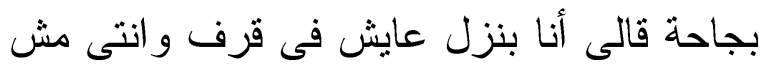

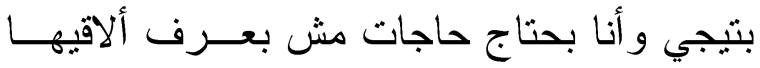

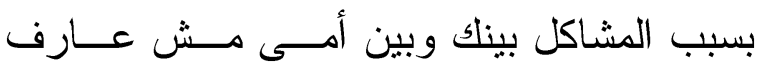
أر اضي أمى و لا عارف أمارس حياتي))، وتثول

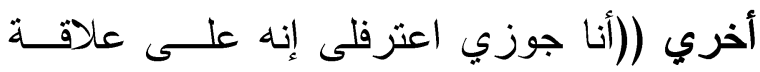

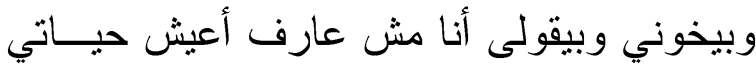
زي أى حد متزوج))، أخرى تقول ((حماتى من غلها بتقولى ده إنتي خليت جوزك بقي يبص بره بره

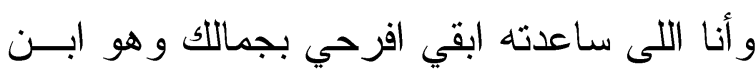
أمه لما بكلمه يقولى متسمعيش الكلام ده وقدامها

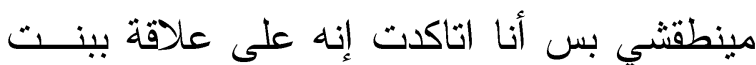

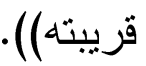
و لاحظت الباحثة ضعف شخصيه الزوج

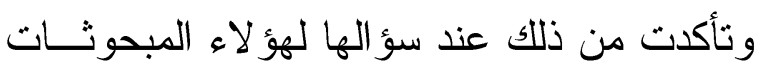

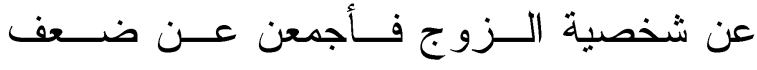
شخصيته أمام و الدته. r- مشكلات نفسية وجسدية:

كثفت الدراسة الميدانية عن أن هنــاك مجموعة من المشكلات النفسية و الجسدية الناجمة عن الصر اعات بين أم الزوج و الزوجة اتفقـــ عند بعض الحالات واختلفت عند البعض الآخر

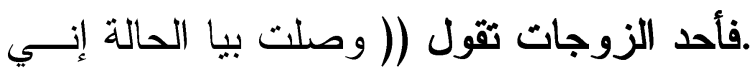




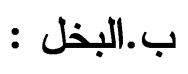

كشفت الدراسة الميدانية عن بخل بعض

الأزواج على زوجاتهم فزوج يبخل على زوجته

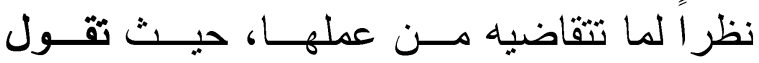
زوجته((جوزى لما بطلب منه حاجه مبيرضاش ويقولي منتى بتقبضي علي قلبك قد كده))، و آخر يبخل على زوجته و لا يبخل على أى فرد مسن

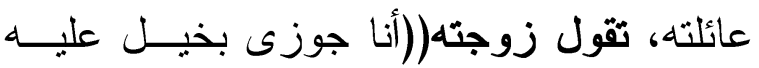
بمعني الكلمة ومبيرضاش يصرف عليه ويقولى روجلى انتى معكيش عيال بتصرفي في ايه وقاعدة عند

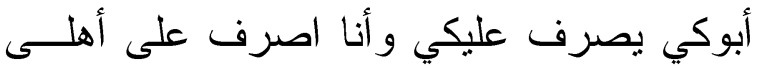

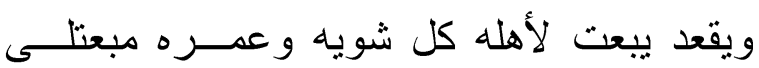

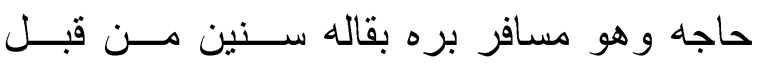

$$
\text { جوازى) () واجه }
$$

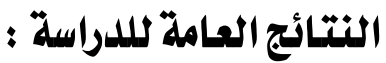

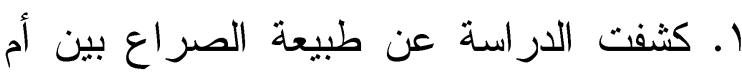

الزوج و الزوجة النى تمنلت فى أنها كانت من جانب أم الزوج بنسبة (•٪\%)، بينما القلة من الصر اعات كانت من جانب الزوجة

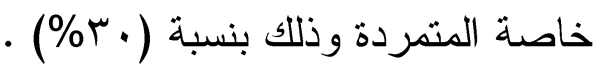
r. كثفت الدراسة عن العو امل المسببية

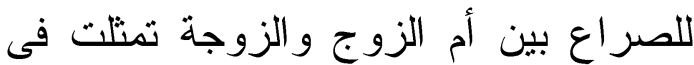
العوامل الاجتماعية و الثقافية؛ كثقافة النظرة السائدة للزوجة، صراع الاجبال، و التتشئة الاجتماعية، وسائل الاعلام والتواصل لاصلئل الاجتماعي. و العوامل الأسرية كالغيرة، و الخدمة المنزلية، و والعوامل الاقتصادية؛

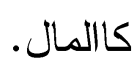

طول عندي قلق وتوتر وعصبية ولمسا عـدت بزعل بيجلي أزمة على صدري بتزيد مع الزعل أنام فيها أقل حاجة شهر وبيغمي عليه كثير لأن أنها ضغطي على طول بينزل وجالى الســكر بعـــ مولدت آخر مرة)) ، وتقول أخري ((أنا معتش لين بعرف أنام على طول بيجيلي كو ابيس و أحلم إنها بتقوله طلقني و هو بيسمع كلامها في الحلم غيـر إن جالى السكر وز اد عليه بسـبـ إن مكانثــي ليكي

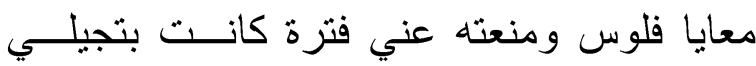
غيبوبة) () وتسرد أخري عن تضررها ليس نفسياً و لا جسديا فقط و إنما عصبيا، حيث إنها تتعرض لحالة صرع معبرة عن ذلك عنـد حسدوث أي

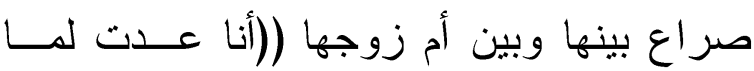
بيحصلي مشكلة بيجيلــي حالــة زي الانهيــار بالصريخ وتثنجات وتقوس بجسمي) (بنئه

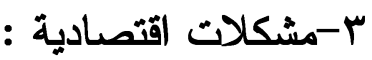
أ. عدم تحمل مصاريف الزوجه:

كثفت الدراسة الميدانية عن عدم تحمل بعض الأزو اج مصاريف الزوجة بســبب عـدم اهتمامه بزوجته أو خوفه مــن انفاقــهـ عليهـا لارضاء أمه خاصةً إذا كانت تعمل، وتعبر أحد الزوجات عن ذلك بقولها((أنا جوزي مبيهــتشش يبعتلى نهـائي أي حاجــة و لا بيهــتم أصــلاً بوجودي))، وثانية تقول((جوزي بيبعت لأمسـه

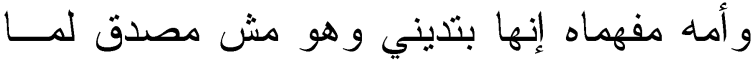
بقوله الحقيقة))، ثالثة تحكي((جوزى مش عارف أصلا بصرف إزاي ولا بيسألنى عشان عــارف لهان

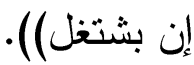


(') كمال الدسوقي: "الاجتماع ودراسة المجتمع"،

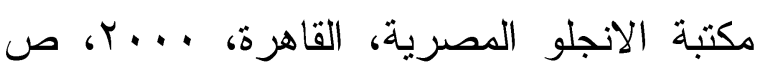

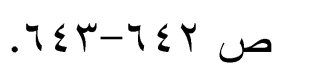

(r) كريم فخري هلال، ساهرة قحطان عبد الجبار: "المشكلات التي تواجه طلبة الكلية التربوية المفتوحة في محافظة بابل من وجهة

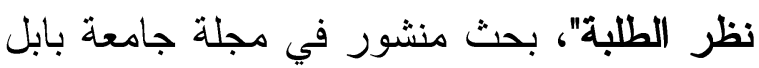
العلوم الإنسانية، المجلد 11، العدد؟، كلية التزبية - جامعة بابل، • ( • r، ص 9 ب.

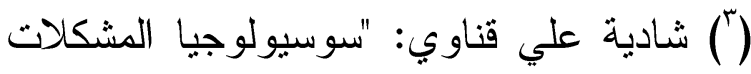
الاجتماعية وأزمة علم الاجتماع المعاصر"، دار

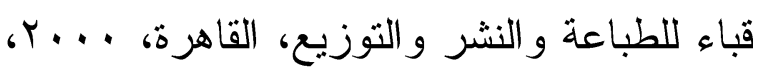
ص

(ا) محمد القريوتي: السلوك التظيمي دراسة

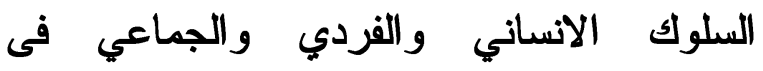
منظمات الاعمال، الطبعة الخامسة، دار و وائل

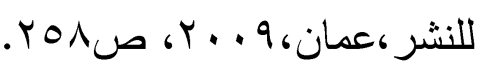

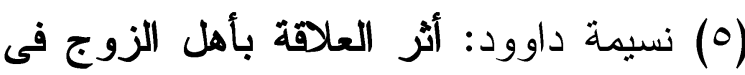

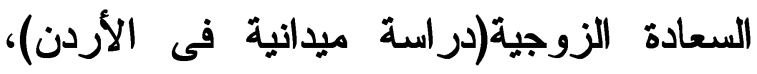
ورقة بحثبة منشورة بجلة اتحاد الجامعات

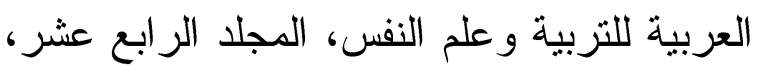

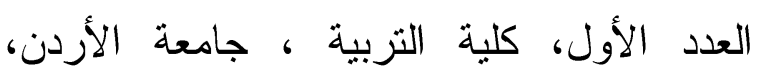

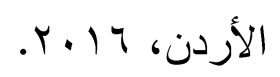

(آ) ايمن صالح: تدخل الاهل في حياة الزوجين وأثر ذلك في حدوث الطلاق ، ورقة بحثية

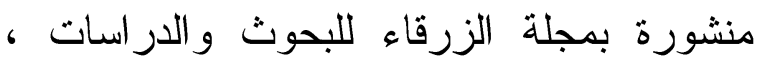
المجلد السادس، العدد الثاني ، جامعة الزرقاء

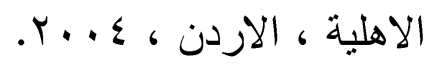

(7)Bryant, C. onger. R .D. \& Meehan, J.

:The Influence of in-laws on Change in r. أظهرت الدراسة المشكلات الناجمة عن

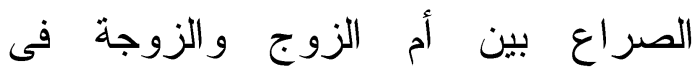
المشكلات الاجتمكاعية

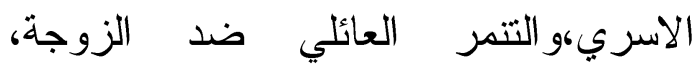
وضعف الروابط العائلية بين أسرني الزوج و الزوجة، وارتكاب الجرائم، و التهديد بالزواج من أخرى، والخيانة الزوجية،

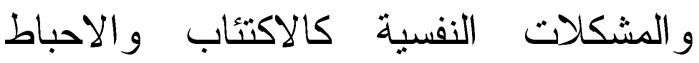
و القلق و التوتز واضطرابات فى النوم و الارق، و الجسدية كالاضطر ابات فى الجهاز

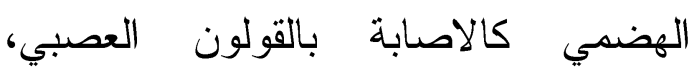
و أمر اض مزمنة كالاصابة بالسكر، ومشاكل فى الجهاز التتفي كالاصابة بحساسية

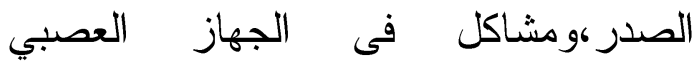
كالصر ع،ومشكلات اقتصادية؛كعدم تحمل

$$
\text { مصاريف الزوجه، و البخل. }
$$

\section{توصيات اللدراسة :}

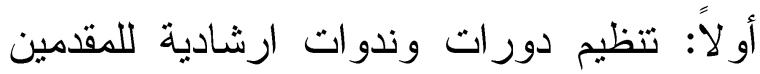

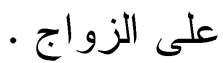

ثانيًا: إعطاء دبلومات خاصة بلز بالحياة الزوجية،

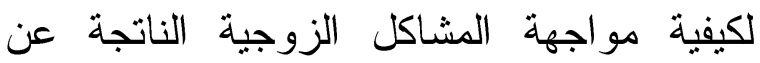
الصر اعات بين أم الزوج و الزوجة.

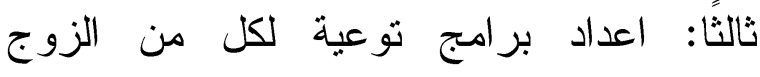
و الزوجة بالحقوق و الواجبات تجاه زوجه وأهله وأهل زوجه بحيث يقوم كل منهما بدوره بعيداً عن الصر اعات و المشاحنات.

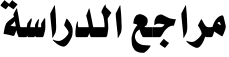


(9) Turner, M. J., Young, C. R., \& Black, K.I. : Daughters-in-law and mothers-inlaw seeking their place within the family: A Qualitative study of differing viewpoints. Family Relations, 2006
Marital Success. Journal of Marriage and Family,2001.

(8) Sliverstein, J. L.: The Problem with the husband's family

, Journal of family Therapy,1990. 